\title{
Computer aided diagnosis of abdominal pain: implementation difficulties in the North Western Region
}

\author{
J.-A. CLYMA* \& G. LANCASTER ${ }^{+}$
}

${ }^{*}$ Centre for Cancer Epidemiology, Christie Hospital NHS Trust, Kinnaird Road, Withington, Manchester and ${ }^{+}$Centre for Cancer Epidemiology, Christie Hospital NHS

Trust, Kinnaird Road, Withington, Manchester

\section{SUMMARY}

During 1987 a system for the computer-aided diagnosis of abdominal pain was introduced on a trial basis in seven district health authorities in the North Western (NW) Region. Despite good reports of the system from other areas, by the end of a 12 -month period only two of the seven districts continued to use it in the routine management of patients.

A study was undertaken to determine the difficulties that had been encounteredo and the way in which these had hindered successful implementation of the system.

Information was obtained by interview with key personnel involved in the trial, which included the chief executive in each district, a consultant designated as responsible for the system and clerical staff.

The study identified three main factors undermining the implementation of the system: a lack of consultant support; the negative attitude of junior doctors; and inadequate clerical support.

\section{INTRODUCTION}

The computer aided system (CADAP) to assist in the diagnosis of patients presenting with acute abdominal pain was first introuduced in the early seventies (Horrocks et al., 1972). A prerequisite for use of the system is that clinical data for each patient are recorded on a structured data sheet by the clinician. These sheets are then entered into a computer. Therefore, the doctor and the computer assimilate the same clinical data, with the doctor reaching his or her diagnosis using past experience and knowledge, and the computed diagnosis being based on probabilities derived from a large database of previous case histories. In an early trial

Correspondence: J.-A. Clyna, Research Associate, Centre for Cancer Epideniology, Christie Hospital NHS Trust, Kinnaird Road, Withington, Manchester M20 9QL, U.K. 
of the system (de Dombal et al., 1972) the diagnostic accuracy of clinical staff was examined and compared to that of the computer. Accuracy ranged from $72 \%$ of cases at house surgeon level, to nearly $80 \%$ at consultant level. The computer attained a diagnostic accuracy of nearly $92 \%$ illustrating its potential as an aid to the clinician.

The system can be used by the clinician in a number of ways, namely: for decision support in real time (direct feedback); to provide a diagnosis for future reference (indirect feedback); and/or in its capacity as a teaching package. In a recent study involving junior staff in two hospitals (de Dombal et al., 1991), a baseline survey showed diagnostic accuracy ranging from 47 to $53 \%$ - figures consistent with other studies (Adams et al., 1986). After implementation of the CADAP system it was found that use of the structured form alone improved diagnostic accuracy by approximately $7 \%$. There was further improvement of approximately $15 \%$ when combining use of the form with computer feedback (either directly or indirectly), and finally accuracy rose by $20 \%$ when the structured form and teaching package were used together. These findings suggest that CADAP will improve the ability and confidence of junior doctors in diagnosing patients presenting with acute abdominal pain, and thereby reduce the number of unnecessary surgical interventions.

In 1987 the North Western Regional Health Authority decided to investigate the feasibility of implementing the CADAP system in the NW Region. Each District General Manager and Chairman was invited to take part in the study and seven districts volunteered. In order to participate, each district needed to: (1) buy a microcomputer; (2) pay someone at a clerical level (a minder) to put information into the computer and produce output; and (3) have consultants committed to encouraging the junior doctors to use the system.

The study involved an initial 6-month baseline period in which the doctors practiced as normal without any diagnostic aids, and data were collected on the outcome of patients presenting with cases of acute abdominal pain. Following this, there was a 12-month period in which doctors were provided with structured data collection forms plus computer aided support. Despite the success reported in earlier trials, by the end of the North West trial only two of the original seven districts continued to use the system.

\section{METHODS}

A letter was sent from the Regional Medical Officer in November 1991 to the key personnel in each district who were responsible for the system (usually one or two consultants and the chief executive). They were asked if they would take part in an interview to discuss the trial and any problems that had been encountered. Fifteen of the seventeen people approached agreed to take part and were interviewed during December 1991 and January 1992. In three districts the minders also participated in discussions. At the interview each person was given a list of questions which addressed different aspects of the organization and use of the system as well as interaction of key personnel. 


\section{RESULTS}

Since the trial period, two districts have continued to use the system, while five others have not. Two districts did not complete the trial period. The CADAP computer was sited in the accident and emergency department (A\&E) in four districts, in the surgery department in two districts and in a secretarial office in one district.

While the aim of this study primarily was to determine problems in setting up the CADAP system, a number of positive elements were noted. Regardless of current use, all districts agreed that, in theory, the system was a good idea and the CADAP team based in Leeds had been very supportive and helpful throughout the trial. The structured form was commended by four districts and the computer was described by one district as very 'user-friendly'. Another district noted the positive aspect of presenting a wide variety of disorders from a large database to junior doctors, which gave them more awareness of the less common problems.

\section{IMPLEMENTATION DIFFICULTIES}

\section{Role of chief executive}

In each district the opinion of the chief executive ( or equivalent) was sought, buto in only one case did this person have a good overview of the system. Most had been instrumental in the early stages, organizing the purchase of equipment and appointing staff, however, their future involvement was minimal. Their knowledge of implementation difficulties came second-hand from the consultants and minders, and often this information seemed to be sparse.

None of the chief executives reported any problems with purchasing and installing the CADAP system. However, a breakdown in communication between the chief executive and consultant in one district during these initial stages, was felt to be a major reason for failure of the CADAP trial.

\section{Clinical opinion}

The introduction of the CADAP system caused mixed feelings among consultants in all districts. Individual concerns included:

(1) initial fears that the computer's diagnosis might take precedence over a clinical diagnosis;

(2) resentment toward the installation of the CADAP system when it was believed that the department in which it was to be installed was understaffed, underfunded or had greater need for other items of equipment;

(3) resistance to the system because it was an outside initiative, not brought about or requested by the hospital in which it was installed, and therefore felt to be imposed on them and;

(4) the opinion that in good teaching hospitals juniors were well trained by the consultants and there was perhaps no need for the CADAP system. 
The attitude of junior doctors was also reported to vary widely:

(1) on being introduced to the system, some found it simple and beneficial to use. Others merely completed the forms to satisfy their senior doctors, while some saw the system as irrelevant and were quoted as spending more time trying to 'fool' the computer than learning from it;

(2) junior staff were invariably busy and many were thought to see the CADAP system as just another job being added on top of many others; and

(3) if the consultants were not actively encouraging the junior doctors to use the system, they soon stopped completing the forms.

\section{Administration}

During discussions relating to the implementation of CADAP, it was generally agreed that a minder would be appointed who would have specific (paid) time set aside for the project. In reality the conditions varied widely:

(1) in only two districts was the minder in post at the time of implementation, and allocated with the necessary time and funds to collect forms and enter data;

(2) in one district the hours for the minder post were allocated to Saturday morning. This was not a popular option and when the original minder left the post, it was impossible to find a replacement;

(3) in another district the minder was appointed late - well after the system was implemented, which meant there was a large backlog of forms to deal with; and

(4) in three districts the minder position was filled by medical secretaries who were expected to carry out the CADAP work in addition to their normal duties. In one of these districts the minder not only collected forms and entered data onto the computer, but often had to complete the forms from doctors' case notes. Of these three districts, one changed the working conditions for the minder after a period of time.

With regard to the level of responsibility the minder held, this also varied widely. In two districts the minder was almost totally responsible for the running of the system and had the consultants to refer to if problems arose. In one district the minder and consultant worked as a team in implementing the project, and in the other four districts the consultant had overall responsibility. In the districts where minders were seen to be responsible for the system, not only collecting forms and entering data, but also running induction sessions and tutorials, their job was almost impossible without the full backing of the consultants concerned. It proved difficult in one district to get the junior doctors to attend tutorial sessions, or to insist that they completed the forms.

\section{Other problems}

Concerns were expressed regarding feedback from the trial. In one district there were complaints that although they received data from the trial study relating to the project as a whole, they did not receive data specific to their hospital. Without evidence that the system was actually improving accuracy among staff, there was little incentive to continue with the project. Two districts also commented that the data returned were not very meaningful. They suggested that there may 
have been a reporting bias, as forms were not completed for all patients admitted with abdominal pain, e.g. it may have been that only in easier cases were forms completed.

Other initiatives being introduced in the hospitals sometimes caused a conflict of interest: in one of the districts implementing the CADAP system, there was also another computer system being installed for general audit purposes. As this second system had been initiated by hospital staff, the interest of consultants lay more with their own project than with the CADAP project.

The size of the hospital and level of staffing was proposed by one district as being a source of problems. In larger hospitals where many clinical teams operate, the number of junior doctors needing induction to the system and the workload generated from it, would place a strain on a single minder.

The choice of location of the computer (either A\&E or surgery) may have caused problems. In one district it was reported that when junior doctors from one department who were using the CADAP system saw that junior doctors from another department did not have to undertake this extra work, there was a decline in cooperation.

Induction courses and tutorials for junior doctors varied somewhat. All districts appeared to have a form of induction course in which the CADAP system was introduced. Beyond this however, only three districts instituted tutorial sessions, and only one of these on a regular basis. Those who did not run teaching sessions commented that they thought the system was so simple no further tuition was needed, and that junior doctors were responsible for themselves if they wanted to use the teaching package.

\section{CONCLUSION}

The reluctance of some clinicians to adopt the use of computers for support in real-time decision making and patient management, especially when the computer may seem to take over their diagnostic and decision-making functions, has already been reported, (Balla et al., 1989; de Dombal et al., 1991).

In this study, the main causes of failure in implementation seemed to hinge upon a lack of leadership from consultants. Concerns about the system resulted in a lack of enthusiasm from consultant staff, which inevitably had a negative effect on junior doctors who queried the relevance of the system and objected to the extra workload it caused. Lack of support for the minders resulted in too few working hours, and/or too much responsibility.

de Dombal et al. (1991) suggest that those who do not wish to use the computer for direct feedback use the system as a teaching package. They showed that this seems to give results at least as effective as real-time support, and might be just the solution for those wary of direct computer support. 


\section{RECOMMENDATIONS}

Each person interviewed was asked what advice they would give to someone thinking of setting up CADAP in their district. This information has been pooled to make the following recommendations for successful implementation.

(1) It is important to involve all key personnel in initial discussions as exclusion can lead to 'bad feeling' and non-participation e.g. set up a project team.

(2) The implementation needs to be planned properly and tested at each stage.

(3) Special consideration should be given to the location of the computer e.g. A\&E, surgery, a computer in both departments, or elsewhere.

(4) It is vital that the system is consultant-led but easy to manage.

(5) Both the consultant(s) and minder need to be committed to the system and must understand why the system is being used i.e. that it is a diagnostic/teaching aid, and does not over-ride the clinician's judgement.

(6) The consultant(s) must be dedicated to encouraging new junior staff to use the system e.g. the system could be introduced to them as part of their initial induction.

(7) Special attention should be given to the use and completion of the structured form.

(8) The minder must be someone to whom the doctors will relate, since he/she will be involved in their training.

(9) The minder must be given enough working hours per week to complete his/her tasks.

Each of these recommendations requires careful consideration if the CADAP system is to be implemented successfully. Sensible planning, adequate resources, strong leadership and good communication and cooperation between consultant, minder and junior doctors are all integral parts of the process; but ultimately the consultant must be in favour of using the system.

\section{ACKNOWLEDGEMENTS}

The authors would like to express their thanks to the participants from the various districts and hospitals (managerial, clinical and administrative) who provided us with information and advice, and to Dr Jo Walsworth Bell for her support. This study was funded by the North Western Regional Health Authority.

\section{REFERENCES}

Adams I. D., Chan M., Clifford P. C. et al. (1986) Computer aided diagnosis of acute abdominal pain: a multicentre study. British Medical Journal 293, 800-804.

Balla J. I. Elstein A. S. \& Christensen C. (1989) Obstacles to acceptance of clinical decision analysis. British Medical Journal 298, 579-582. 
de Dombal F. T., Leaper D. J., Staniland J. R., McCann A. P. \& Horrocks J. C. (1972) Computer-aided diagnosis of acute abdominal pain. British Medical Journal 2, 9-13.

de Dombal F. T., Dallos V. \& McAdam W. A. F. (1991) Can computer aided teaching packages improve clinical care in patients with acute abdominal pain? British Medical Journal 302, 1495-1497.

Horrocks J. C., McCann A. P., Staniland J. R., Leaper D. J. \& de Dombal F. T. (1972) Computer-aided diagnosis: Description of an adaptable system, and operational experience with 2,034 cases. British Medical Journal 21, 5-9. 